\title{
Virtual neutron scattering experiments \\ - Training and preparing students for large-scale facility experiments
}

\section{Julie Hougaard Overgaard}

PhD-student

Niels Bohr Institute, University of Copenhagen

\section{Jesper Bruun}

PhD, Assistant Professor

Department of Science Education, University of Copenhagen

\section{Michael May}

PhD, Associate Professor

Department of Design and Communication, University of Southern Denmark

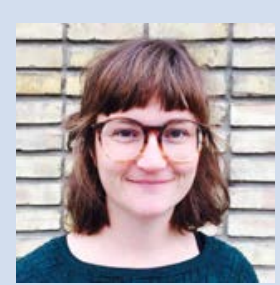

\section{Linda Udby}

PhD, Associate Professor

Niels Bohr Institute, University of Copenhagen
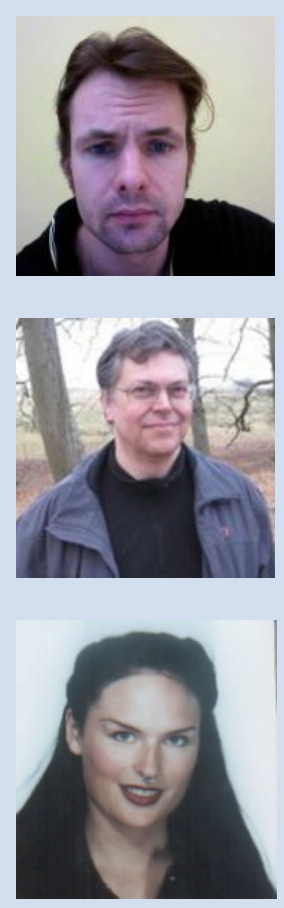


\section{Dansk resumé}

Vi beskriver, hvordan virtuelle eksperimenter kan udnyttes i et læringsdesign ved at forberede de studerende til hands-on-eksperimenter ved storskalafaciliteter. Vi illustrerer designet ved at vise, hvordan virtuelle eksperimenter bruges på Niels Bohr Institutets kandidatkursus om neutronspredning. I den sidste uge af kurset, rejser studerende til et storskala neutronspredningsfacilitet for at udføre neutronspredningseksperimenter. Vi bruger studerendes udsagn om deres oplevelser til at argumentere for, at arbejdet med virtuelle experimenter forbereder de studerende til at engagere sig mere frugtbart med eksperimenter ved at lade dem fokusere på fysikken og relevante data i stedet for instrumenternes funktion. Vi hævder, at det er, fordi de kan overføre deres erfaringer med virtuelle eksperimenter til rigtige eksperimenter. Vi finder dog, at læring stadig er situeret i den forstand, at kun kendskab til bestemte eksperimenter overføres. Vi afslutter med at diskutere de muligheder, som virtuelle eksperimenter giver.

\section{Abstract}

We describe how virtual experiments can be utilized in a learning design that prepares students for hands-on experiments at large-scale facilities. We illustrate the design by showing how virtual experiments are used at the Niels Bohr Institute in a master level course on neutron scattering. In the last week of the course, students travel to a large-scale neutron scattering facility to perform real neutron scattering experiments. Through student interviews and survey answers, we argue, that the virtual training prepares the students to engage more fruitfully with experiments by letting them focus on physics and data rather than the overwhelming instrumentation. We argue that this is because they can transfer their virtual experimental experience to the real-life situation. However, we also find that learning is still situated in the sense that only knowledge of particular experiments is transferred. We proceed to discuss the affordances of virtual experiments.

\section{Introduction}

Modern experimental physics research often involves the use of very large and very complex instruments. The development of these instruments is intimately tied to the physical phenomena they are meant to investigate. For example, some of the instruments at Conseil Européen pour la Recherche Nucléaire (CERN) are dedicated to searching for very particular fundamental particles. Telescopes and array of telescopes are dedicated to observations of very particular colours of light (wavelengths). Each instrument is dedicated to a very particular kind of measurement. Neutron scattering instruments are also dedicated to a particular kind of measurement, namely the detection of neutrons. The real field of interest is, however, the sample, which is placed in the instrument and with which the neutrons interact. The neutron scattering 
technique utilizes that the neutron - popularly known as one of the building blocks of atoms - can investigate the structure, properties, and dynamics of for example crystals, proteins and archaeological items. Many varieties of the neutron scattering technique and corresponding neutron instruments exist and they can be useful in many aspects of material science, which are represented in such diverse fields as physics, chemistry, biomedicine and even cultural heritage.

The general idea is to produce neutrons, shoot them into a physical sample, and then measure how they were affected by the interaction. Because of their complexity, building and maintenance costs, these instruments are rare. Neutron experiments are conducted at large-scale facilities, and researchers must apply for beam time - in which they can perform their experiments with the relevant instrument. It is essential that the experiments succeed in the allocated period of time and there is therefore little room for error from e.g. students in the learning process.

This urgency contrasts educational findings that making mistakes during learning can be essential for developing physics competencies (e.g. Mason, Yerushalmi, Cohen, and Singh 2016). The neutron scattering community needs to educate more neutron scattering scientists, but because of the versatility of the neutron scattering technique, there is also a need to educate scientists with different physics background and even with a non-physics background (Udby et al. 2013). However, hands-on training on the instruments is limited due to operating costs.

One could argue that the problem of limited hands-on training possibilities is not new. For example, pilots have long been trained using simulators (see e.g. the textbook on the matter by Rolfe and Staples 1988). Here, learners use the simulations to master the devices they will be using to handle a range of predefined situations. The outcome of training is a predictable set of skills that can be employed in a range of situations. What sets neutron scattering experiments at large-scale facilities aside from these situations is that there is not only a set of predefined situations to be learned. Learners also need to learn how to effectively deal with situations, which are new even to experts in the field. This requires deep knowledge, the will and ability to act with experiments both alone and in collaboration with others. It requires that the learners feel like part of a team, because at times only a team effort will help solve the problem at hand. In other words, it requires the competency to do neutron scattering experiments.

The problem we face, then, is how we can help students build their experimental competency within the field of neutron scattering. As argued above, there is a tension between allowing students to learn by doing - and thereby allowing for mistakes - and the high-stakes nature of large-scale facility experimentation. To address this tension, we have developed a course 
that implements detailed and highly interactive simulations called virtual experiments (VE), which facilitate student engagement with neutron experiments at large-scale facilities.

In this article, we describe the learning design and related choices, which have shaped the course in terms of our intentions, the way the course is implemented and the products students are to make. Our case is the Niels Bohr Institute (NBI) neutron scattering course. The entirety of our data material consists of student products, teacher reflections, student interviews and survey answers, as well as researcher observations. The scope of this article is to elaborate our reflections on the parts of our learning design intended to prepare the students to operate in the experimental setting at a large-scale facility. This task specifically contains learning theoretical reflections on teaching and learning through virtual experiments in a university course and the transition to performing hands-on experiments at a large-scale facility. We focus on student interviews and survey answers and use our experiences with teaching and observing the course as a background. To put students' experiences into context, the next three sections proceed as follows: First, we describe how experienced researchers perform neutron scattering experiments and how some of these researchers use virtual experiments. Second, we describe in brief the didactical models and methods employed and how they may relate to our case. Third, we give an overview of the documentation we use in the article. After describing the case and before concluding the article, we discuss more broadly the affordances of virtual experiments as they relate to hands-on experiments and to the rationale for doing practicals.

\section{How neutron scattering experiments are practiced}

A central part of doing neutron scattering is to do experiments at large-scale facilities. We want students to be able to perform these experiments, so it is natural to provide an overview of the scientific practice. The scientific process can be divided into three major phases: preparation of experiment, running the experiment and finally analysis of data and publication of results.

The simplest neutron scattering instrument consists of a neutron source and a detector. To optimize the number and state of neutrons that make it to the detector, several optical components are used between the source and the detector. The dimensions, composition and order of the optic components are intimately tied to the physical phenomena the specific instrument is designed to investigate. During the experiment, a sample with interesting physical properties is placed so that neutrons will hit it and scatter off of it. The 
patterns that the scattered neutrons make reveal insights into the properties of the sample.

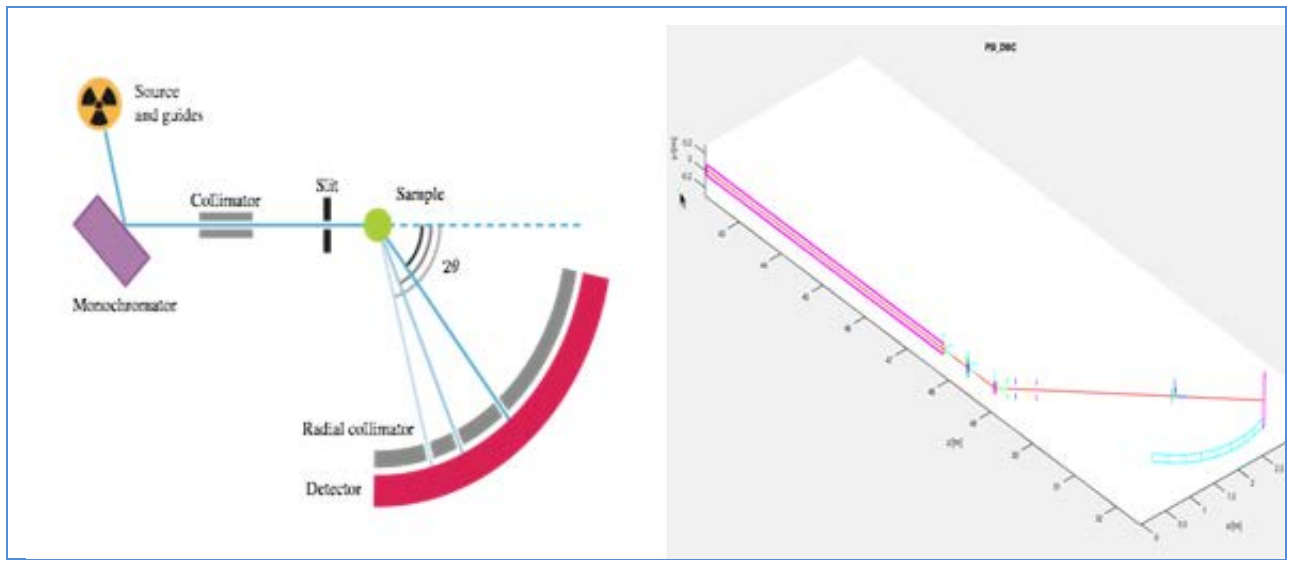

Figure 1. A sketch of a two-axis diffractometer (left) and corresponding virtual experiment ray-tracing overview (right). The different optic components shape and modify the neutron beam as it travels through the instrument.

\section{Preparation of the experiment}

In order to carry out an experiment scientists have to apply for beam-time on a specific instrument several months in advance. A committee decides how the beam-time is distributed, and if they accept the project the scientists are assigned the time they applied for. As stressed before, the facility is expensive to run, and therefore the hours a user has on an instrument should be used in the most efficient way possible. As in many other fields, efficiency comes with experience and practice. Another aspect of efficiency is when the user has some idea of the possible outcomes of the experiment; this could be due to former experiments or simulations. All in all, the users need to be prepared properly not to waste valuable minutes.

\section{Running the experiment}

The next phase, running the experiment, is conducted in collaboration with the instrument technician. This person is assigned to assist the users to monitor the instrument and handle the output data.

A neutron facility can be separated into two parts. The first being where the neutrons are produced, this is called the source. The second part is where the experiments are carried out, the instrument hall. Because of radioactivity the source is always shielded with layers of absorbing material, such as lead, concrete or water. After being produced, the neutrons are guided through a so-called neutron guide to the instrument hall. These places challenge the human senses in many ways. The noise level is high due to pumps and other installations; the instruments are huddled together in a way that makes it difficult to see what part belongs to which instrument. Because of the risk of contamination, eating and drinking is prohibited in the instrument hall. Neutron scattering scientists often stays in the instrument hall for hours to 
watch over their experiment and monitor the data during collection. Students who visit a neutron facility for the first time are often overwhelmed both physically and mentally by the stressful environment in the instrument hall. As one student from our course (see later) puts it:

"I think the most important thing is that when you arrive at PSI
[Paul Sherrer Institute, a large-scale facility] there are
ridiculously many things, so the fact that you have an
understanding of how RITA [one of the instruments] works helps
one to cope with all the mess. There are just so many things you
have to cope with the first time you come to SINQ [the part of the
facility dedicated to neutrons]. There are so many new things,
where you think holy shit, I thought I learned a lot, but oh no ..."
(student, fall 2015, our translation)

When running the experiment scientists sometimes stay near the instrument or monitor the data from a cubicle in the instrument hall. From there they run preliminary analyses and make choices about any changes to the experimental setup.

\section{Analysis and publication}

Part of analysing and writing up for publication will not occur at the facility, but some important groundwork is laid here. For instance, when working in a team of scientists who monitor and make changes in an experiment continuously, keeping a detailed logbook is instrumental to systematically keeping track of what has been done. It is also essential to be able to analyse and interpret data as it is collected to ensure that the results, which are brought back home, are useful. Being able to recognise spurious data peaks and remedy the situation may be what saves another (supplementary) trip to the facility. On-the-fly data analysis can be challenging, as even on the same instrument the data may vary in relation to the phenomena studied.

\section{Virtual experiments for researchers}

While this article will focus on student use of virtual experiments, it is worth noting that experienced neutron scattering scientists also make use of virtual experiments via Monte Carlo based neutron ray-tracing (Lefmann et al. 2008, Udby et al. 2011). A convenient piece of software to construct the virtual experiments in is called McStas (Lefmann and Nielsen 1999). The definition of a virtual neutron experiment in our context is:
"A virtual neutron experiment is a complete simulation of an experiment, from source over sample to detector."
(Lefmann et al. 2008: 97)

That is, a virtual experiment requires building a realistic instrument model in a virtual environment, then implementing a virtual sample, and finally running 
the experiment. This will generate simulated data, which are comparable to real data. We differentiate between a simulation and a virtual experiment in the sense that many things can be a simulation, but it is a virtual experiment only when a virtual sample is inserted into a realistic instrument model.

The simulation software we focus on in this article, McStas, is based on Monte Carlo generated simulations of neutron ray paths. The Monte Carlo method is, in general, a way to perform approximate solutions to complex problems by use of random sampling. The software features a GUI interface that serves as an access point for new users and command-line input for more experienced users. The simple structure of the code procedure and the important benefit in being open source makes it the most used neutron ray-tracing software (Lefmann et al. 2008). Since the release of McStas more and more components are added to the catalogue. When you program a virtual instrument, you simply add the components of the instrument in the order the virtual neutron beam traces to the component. See Box 1. A sketch of the corresponding instrument is seen in figure 1.

Box 1. Example code in McStas.

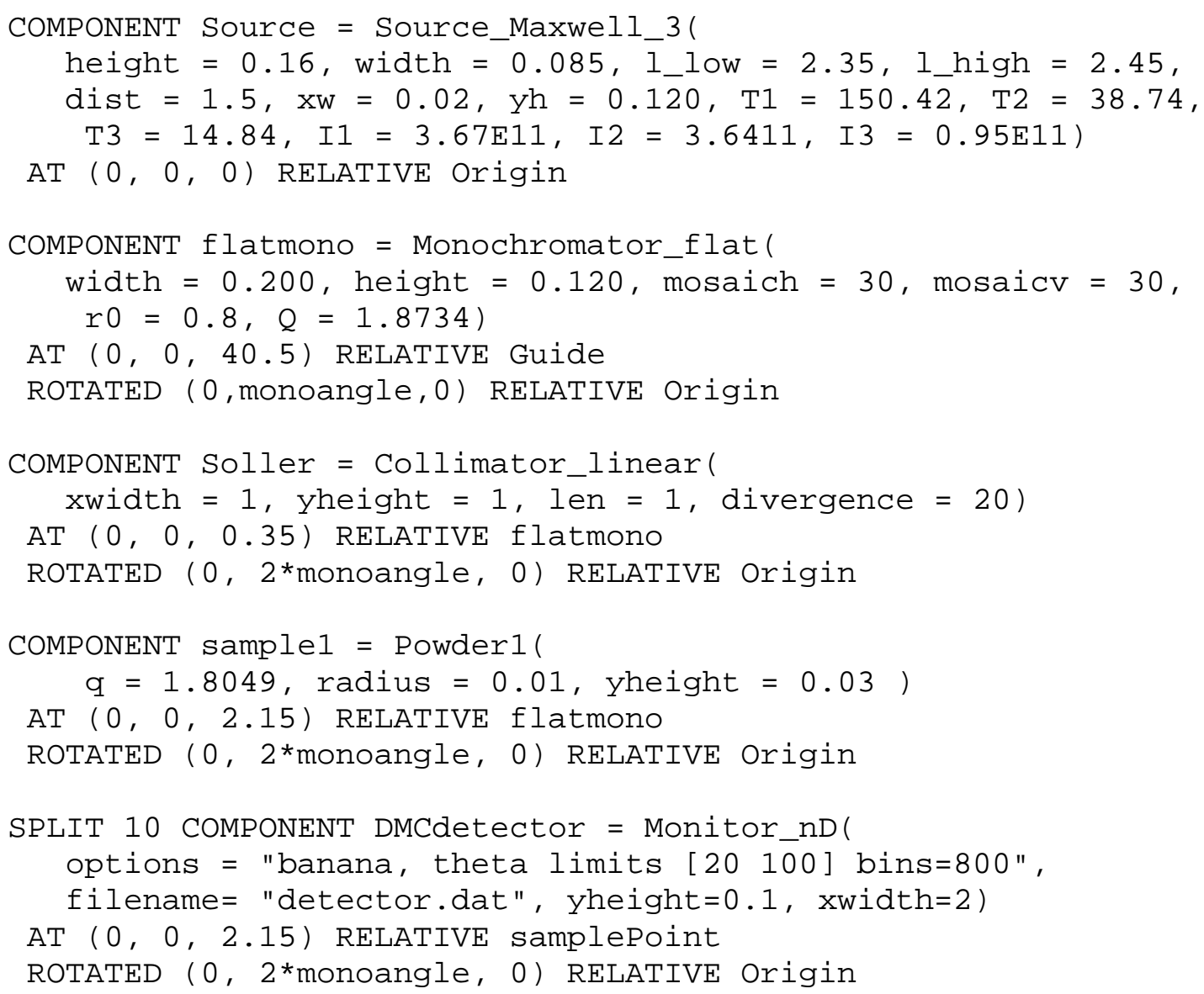


As seen above, the syntax of the code is rather complex and an extra comma or a capital letter at the wrong place can make the simulation fail. If the user types a wrong name or a wrong command, the simulations will be faulty or cause the software to stop running. This often causes trouble for new users.

Fortunately, McStas provides an "insert" folder with the catalogue of existing components. The behaviour and effect of the component depends on different variables. When you choose to insert a component, a new window will open and guide you through which parameters your component should have. See Figure 2.

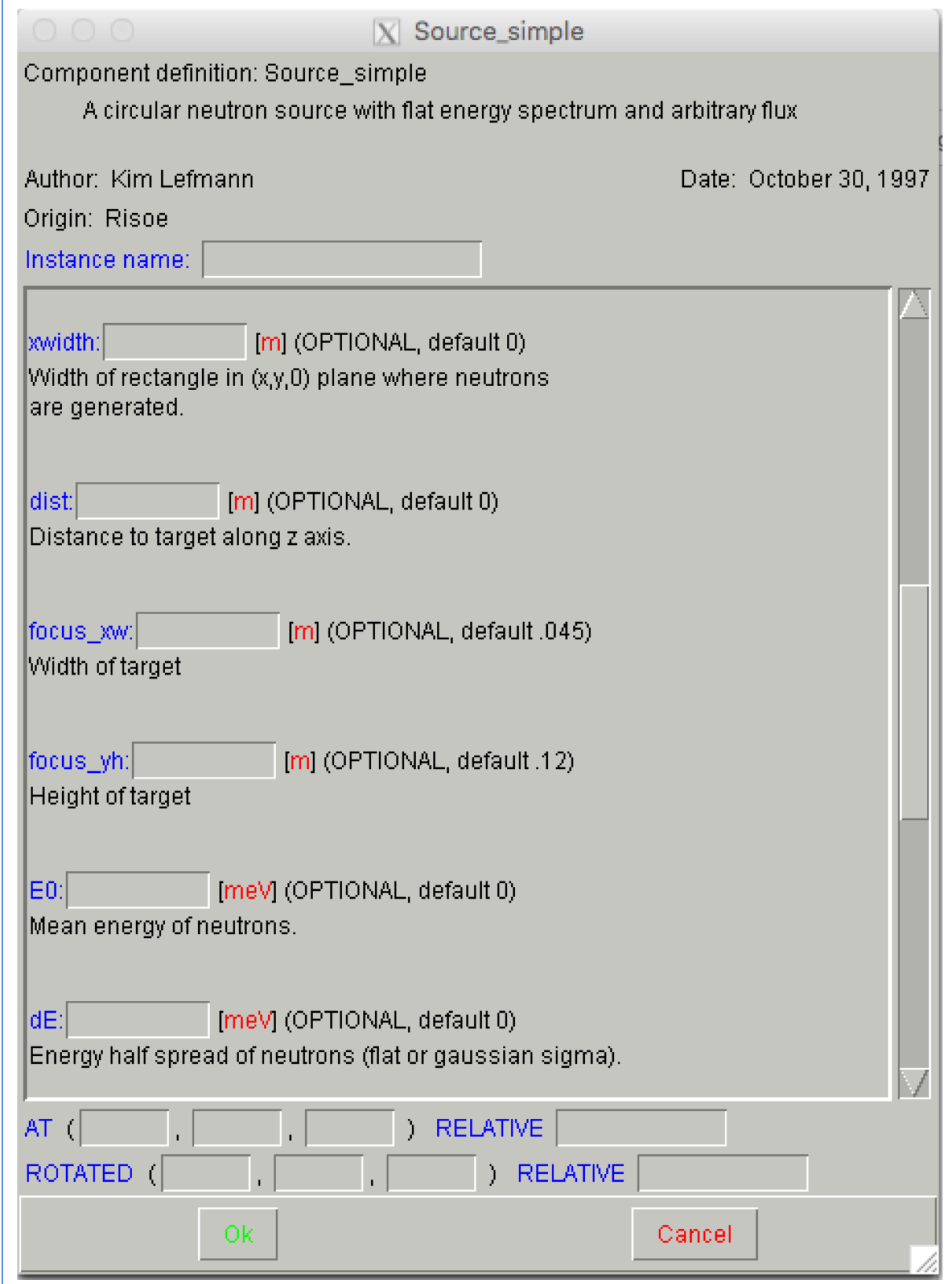

Figure 2. The McStas insert component prompt. 
The components in a virtual instrument have algorithms that simulate the physical properties of the real components. It is possible then to build an instrument virtually by placing the components in the order the simulated neutron beam travels through the virtual instrument, as it would in the real instrument.

Besides being used in connection with teaching, simulations and virtual experiments have played a crucial role in the design process of new physical instruments. At the time of writing this article, the first suite of neutron instruments for the European Spallation Source (Willendrup, Farhi, Knudsen, Filges, and Lefmann 2014) have reached the end of the design process and many important decisions are based on result from simulations (Willendrup et al. 2014). Thus, virtual experiments form an important part of neutron scattering practice.

\section{Classification of McStas as a virtual laboratory}

Before we move on to show how we have designed learning with virtual experiments, we find it useful to classify the software. This highlights some of the didactic affordances and challenges inherent to such a virtual laboratory. May and Achiam (2013) created a formal classification of virtual laboratories in chemistry, biochemistry, and microbiology. Although neutron scattering is a different field, we can classify McStas using their classification. First of all, it is a stand-alone software tool that is used by researchers in the field. Thus, the didactical challenge of using McStas is to introduce it

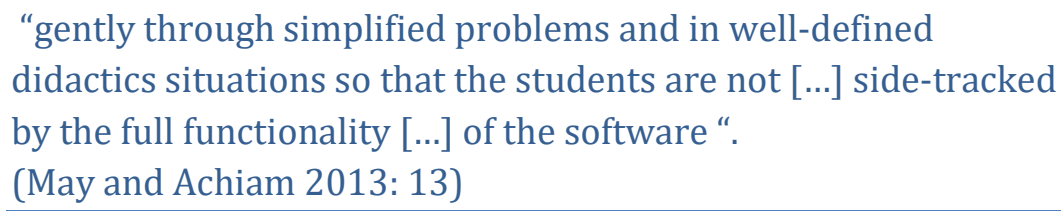

Furthermore, McStas involves animations, which permit interactivity with the content (p. 41) in that students can rotate stylized graphical representations (ray-trace diagrams) of the setup that they have created. Finally, it is a simulation based on an underlying mathematical model of how neutrons behave. However, in contrast to May and Achiam's (2013) classification scheme, McStas does not rely on hyperlinks but on a windows and terminalbased interface. The use of animation and simulation each come with distinct didactical affordances and challenges (May and Achiam 2013). In this case, the affordance associated with animation is primarily that it is a schematization of the relation between an abstract object (neutron beam) and concrete objects (instruments). The primary challenge is if students really believe that the neutron beam looks the way it does on the animation. The affordance of simulations is that they allow for easy and repeated experimentation by students using a model that produces viable outputs. In short, the challenge is for students to not confuse the underlying model with reality. 


\section{Designing learning with virtual experiments}

The motivations for using virtual experiments stem from the limited access to hands-on training, the high level of distractions when doing experiments at the facilities, and the difficulties of visualising the neutron beam inside the machinery. Our expectation for the design is that virtual laboratories can be used to prepare students for hands-on experiments. In this section we relate key theoretical insights to the nature of the activities students should do. That is, this section can be seen as a link between relevant theory and learning design choices. Figure 3 sums up the learning design.

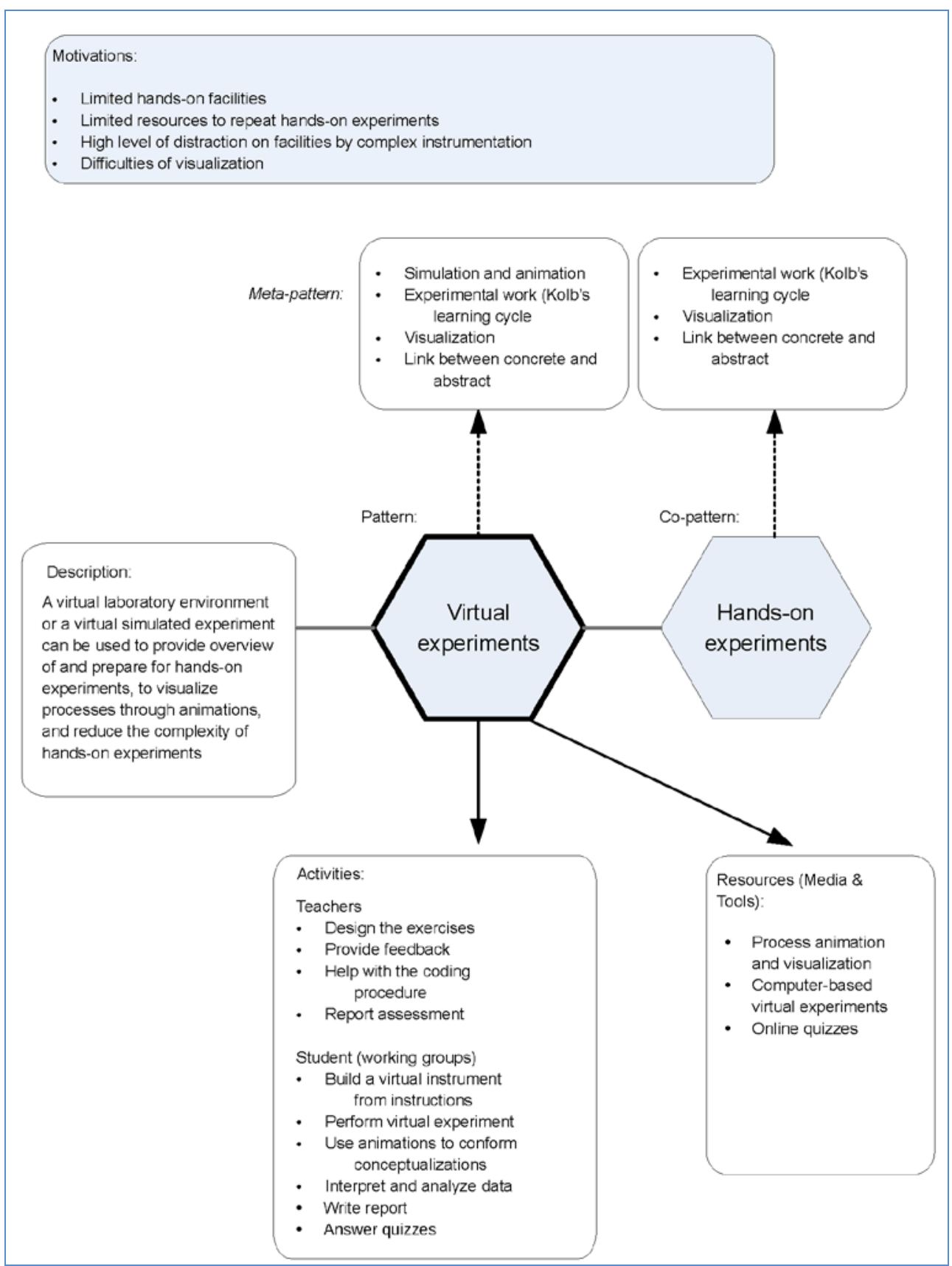


Figure 3. The learning design.

Our view of learning is competency based. In particular, we work with the Bruun's (2012) definition of competency in physics:

"The ability and will to act, alone and with others, using curiosity,
knowledge, skills, strategies, and meta-knowledge as these apply
to physics, in order to negotiate meaning, to develop a distinct
identity within the field of physics, and to participate in relevant
decision making situations."
(Bruun 2012: 36-37)

This view of learning expands on more traditional knowledge views as facts or procedural knowledge to include meta-knowledge, identity and motivation. The process of negotiating meaning is central to this definition of competency. It includes students participating in using the abstractions, tools, symbols, terms, and concepts, and in that process making sense of them in collaboration with others and from their own point of view. But to become competent in physics - here specifically neutron scattering - a student must become able to make sense and properly use representations like the ones in Figure 1 and 2 and Box 1. But this is not enough. Competent neutron scattering scientists are also willing to act; to make decisions (such as changing parameters on an experiment or run the experiment again with new parameters to test a hypothesis), and it becomes part of their identity. In short, becoming competent in neutron scattering involves becoming an accepted part of the community of neutron scattering professionals.

The learning design is meant to facilitate students' building of their competence in neutron scattering. Simulation and animations have the dual function of being part of the tools used in neutron scattering and of preparing students for hands-on experiments at large-scale facilities. By using McStas, students build virtual instruments that mimic real instruments, perform experiments and analyse data.

Our view of learning can be extended by the notion of epistemic framing (Shaffer et al. 2009). An epistemic frame is a hypothesised structure of the culture surrounding a community like neutron scattering. It conforms to our definition of competency in the sense that it includes skills and knowledge. However, an epistemic frame also specifies values and epistemology. Values are seen as the particular shared beliefs held in the community (for example, that neutron scattering is an important and relevant field). We see the development of these beliefs as part of the development of an identity with the community. Epistemology is described as the "the warrants that justify actions or claims as legitimate within the community" (ibid. p. 4). The frame can be "used when an individual approaches a situation from the point of view (or in the role) of a member of a community" (ibid. p. 4). We see the development of 
warrants as part of the development of strategies, meta-knowledge, and being able to participate in decision-making.

The goal is for students to develop their competency in neutron scattering, as they become part of the community. We believe that this can happen to some extent during course work with simulations, but mainly during a visit to a large-scale facility. Becoming part of the community depends on whether their contribution is valued as real research. In the next sections, we elaborate on how the course intends this to happen.

\section{Experiential learning}

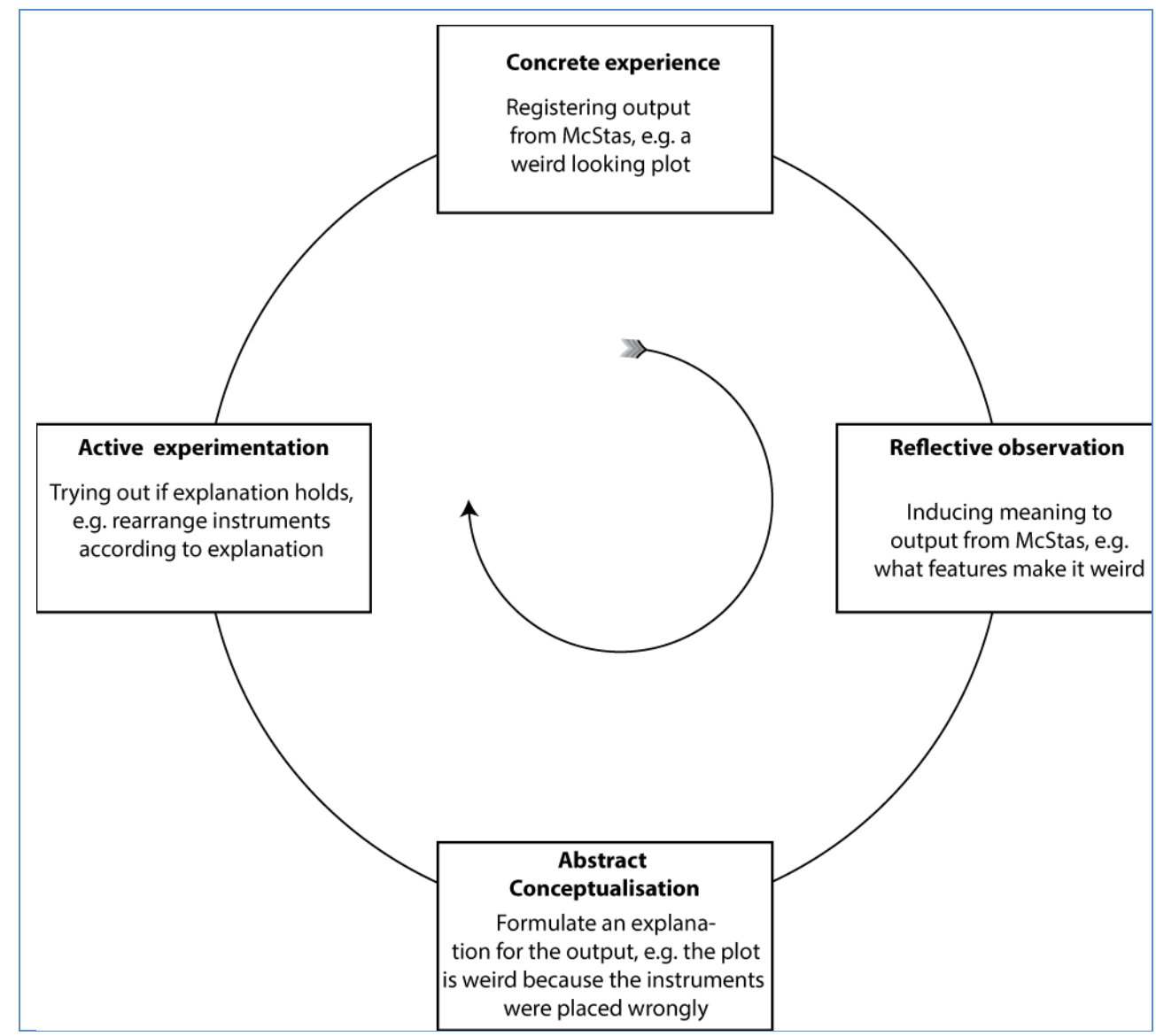

Figure 4: A simplified version of Kolb's learning cycle illustrating a potential learning process.

We have chosen Kolb's experiential learning theory (Kolb and Kolb 2012) as a basis to describe how students work with virtual experiments. When working with virtual experiments, students will have a number of direct experiences. For example, outputs from the experiments could be a graph, an error, an input box, or a schematic drawing of the experiment. When designing learning, one should then design activities that prompt students to reflect on their experiences. Why does the graph look like it does, why is there an error, what values should be put in the box and so on. Making sense of the experience by use of these kinds of prompts, students should then conceptualise the 
experience in a more abstract manner - for example an explanation that answers the prompts. Student explanations should be of a nature that will allow them to use them to experiment further; they need to formulate and execute (a set of) tasks that will test whether their explanation holds. In a virtual laboratory setting, this would lead to a new output for which the circle could repeat. Kolb's learning cycle (Kolb 2014) for our situation is illustrated in Figure 4.

The purpose of these experiential learning cycles can be further illuminated through Gee's (2003) exposition of computer-games as learning machines. Gee (2003) notes that "good games operate at the outer and growing edge of a player's competence, remaining challenging, but do-able" (p.2), to produce cycles of expertise, where players are presented with challenges that makes them "rethink their now taken-for-granted mastery and to integrate their old skills with new ones" (p. 3). He casts games as a way for learners to be producers and not consumers, which is also the essence of contemporary constructivist teaching (Biggs and Tang 2007). In our case, there is no computer game, but it is like a didactic game (Winsløw 2006). Instructors and teachers present challenges to students in a designed learning environment, and students participate in the game by solving these problems.

Kolb's cycle and to some extent also Gee's cycles of expertise can describe learning experiences in the course setting when students work with virtual experiments, but also when they work with quizzes, reports, and when they interact with the teacher. These other activities will be characterized by different outputs, actions and experimentation. Importantly, the cycle can also describe learning as it progresses with a neutron experiment at a large-scale facility. Here, the output is from the various parts of the experiment, and students should be prompted to engage in reflective observation, abstract conceptualisation and experimentation.

\section{Legitimate peripheral participation}

While the learning cycle as described above mainly attends to the single student, Kolb and Kolb (2012) recognise that the social context has a profound influence on whether the student learns or not. A space must be created to facilitate student engagement in all of the four major activities described above. This space

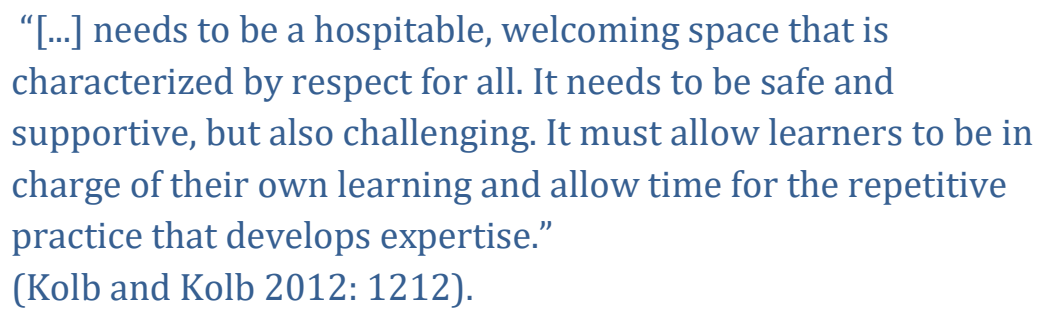


For students to achieve the goals we have for the course, this expertise is crucial.

In fact, one of the end goals of the course (to be described in detail later) is for students to visit an actual large-scale facility and participate in an authentic neutron scattering experiment. They will interact with researchers and technical personnel and thus be a legitimate part of the neutron scattering community. If this interaction is to be successful, we can expect that enculturation students into the practices of neutron scattering starts at home while they learn neutron scattering and make virtual experiments. They must be allowed to fail, while still having the feeling that what they do matter. In other words, their participation may be peripheral, but it needs to be legitimate (Lave and Wenger 1991). Lave and Wenger's prime example of legitimate peripheral participation stems from tailors' apprentices. Apprentice tailors in a particular culture are first allowed to sew in buttons and pockets while the last thing they are allowed to do is cut the fabric. The rationale is that a button can be easily replaced, but the fabric is costly. The same principle can be brought to bear here: Making a fatal mistake in a virtual experiment does not cost much, while the same mistake at the facility can result in e.g. unusable data.

\section{Linking virtual and hands-on representations}

One of the major challenges is to transfer knowledge gained from working with a virtual experiment to the situation of working with an actual hands-on experiment at a large-scale facility. Rebello et al. (2004) has developed a framework to describe transfer, which we find useful. The important question asked within this framework is not how to transfer but what is transferred from one situation to another. For our learning design it means that we have not specified beforehand exactly what students should transfer from a virtual environment to a hands-on situation. Rather we want to find out how they experience the change and what they could use from their previous experiences.

As an example of what we believe could be transferred consider the ability to visualise the flight of the neutron beam in different experiments. This ability is part of the epistemic frame of neutron scattering, and thus relevant for students to learn. Imagining the flight of the neutron beam can be seen as an abstract three-dimensional conceptualisation of what happens in a neutron experiment. In this respect, it is analogous to work done on 3D-visualisations of the Sun-Earth-Moon system (Barnett, Keating, Barab, and Hay 2000). Barnet et al. (2000) found that virtual (animation) modelling supported

"Students' ability to visualize abstract 3-D concepts. [T] he
concept of the line of nodes emerged as a conceptual tool that
became a fundamental component to students' understanding 
the differences and similarities between a full Moon and a lunar eclipse“ .

(Barnett et al. 2000: 140)

In the case of the simulations in this study, students create an experiment, can interact with the schematized animation, and will see the consequences of their design in terms of simulated data. We believe that this can support a link between students' visual imagination and their understanding of neutron experiments, which can be useful for them while doing real experiments.

Another important consequence of Rebello et al.'s (2004) framework is that both the virtual situation and the hands-on situation are learning situations. This means that even if knowledge (for example the ability to analyse a graph) can be activated in a new situation, a student is still learning how to employ knowledge in this new situation. Thus, returning to Kolb's learning cycle, the cycles pertaining to the virtual experiments should - in a transfer situation continue into the hands-on experiments. In general, we expect students to be able to use elements of the epistemic frame they are training during simulation work to further support their development of the epistemic frame while at the large-scale facility.

We see this as a bootstrapping procedure, where students continually use what they have learned to develop their expertise. Here, the transition from the virtual to real experiments can be seen as part of a cycle of expertise where students engage with a new problem which requires in part a "reopening of [their] taken-for-granted tool kit" (Gee 2003) and then engaging this virtually based toolkit in a hands-on situation.

\section{Documentation}

\section{Student interviews and survey answers}

During the years 2014-2015 different surveys have been made after the course to evaluate new learning initiatives on the course in question. To document the students' experiences in this article, we have analysed various citations from open-ended questionnaires and focus group interviews with 6 (fall 2014) and 8 (fall 2015) students present.

We have interviewed students who have taken our course after having visited a large-scale facility. These interviews were focus group interviews (Kvale 2007), which were conducted in an informal setting. The interviews were semi-structured in the sense that we had prepared a set of questions that the interviewer asked, but students were encouraged to discuss their different opinions and the interviewer took up any interesting deviations from the questions. We have transcribed and present what we believe are exemplary 
examples of how students express themselves with regards to different parts of their experiences.

We administered the open-ended questionnaire in the fall of 2015 prompting students to explain how and what they learned from participating in the course and specifically doing virtual experiments. 6 students answered the survey. Their answers have facilitated a few intriguing answers that we also find exemplary.

Our interpretation of student quotes is informed in part by our own experiences from teaching and observing the course, respectively. Two of the authors have taught the course and a third has observed the course before she taught it. We furthermore have access to all student products such as reports and answers to online quizzes/learning activities, which acts as background knowledge for our reflection.

\section{The case: NBI neutron scattering course}

The course, Neutron Scattering in Theory, Simulation and Experiment, is an annual 8 weeks science based course designed for 4 th year students in physics or Nano-science. The course has roughly 20 participants, about half of which are international students. The course consists of 7 weeks blended learning at the Niels Bohr Institute followed by a week hands-on experiments on a largescale neutron scattering facility SINQ located at the Paul Scherrer Institute (PSI) in Switzerland.

\section{Intention - What students should learn}

The learning goals for the course are formulated using the Danish framework for qualification (Danish Ministry of Teaching 2016). The course description (University of Copenhagen 2016) contains the following learning goals in Box 2.

Box 2. Course learning goals.

Knowledge: after the course, the optimal student will be able to: understand the principles, strengths, and weaknesses of neutron scattering, explain the principles of neutron scattering instrument design, have knowledge on radiation security.

Skills: after the course, the optimal student will be able to: apply the theory of scattering, use the simulation program: McStas to perform virtual experiments, plan and perform standard neutron experiments, and report on novel scientific work on a level that could form the basis of a publication.

Competencies: This course will equip the students with the necessary skills for understanding and neutron scattering, a technique that has application for and can be utilized in fields outside physics. 
The course will give the students thorough training in performing and analysing Monte-Carlo simulations.

The students will learn how to perform and report on experiments in a large-scale facility environment, and to perform teamwork on such a facility to obtain the best possible results under strict time constraints.

\section{Implementation - How the course is taught}

Our learning design focuses on incorporating scientific research aspects into the teaching-learning situation. The intention is to allow students to acquire the competencies listed in the course. The students are trained in the different steps of conducting an experiment so that they can take part in the discussions and decisions when doing hands-on experiments in the end of the course.

Virtual experiments are widely used in the course both as learning resources and as assessment. The virtual experiments are constructed as model-based simulations of instruments located at the large-scale facility, which the students will visit during the last week of the course. The virtual data corresponds to what could be measured at a detector.

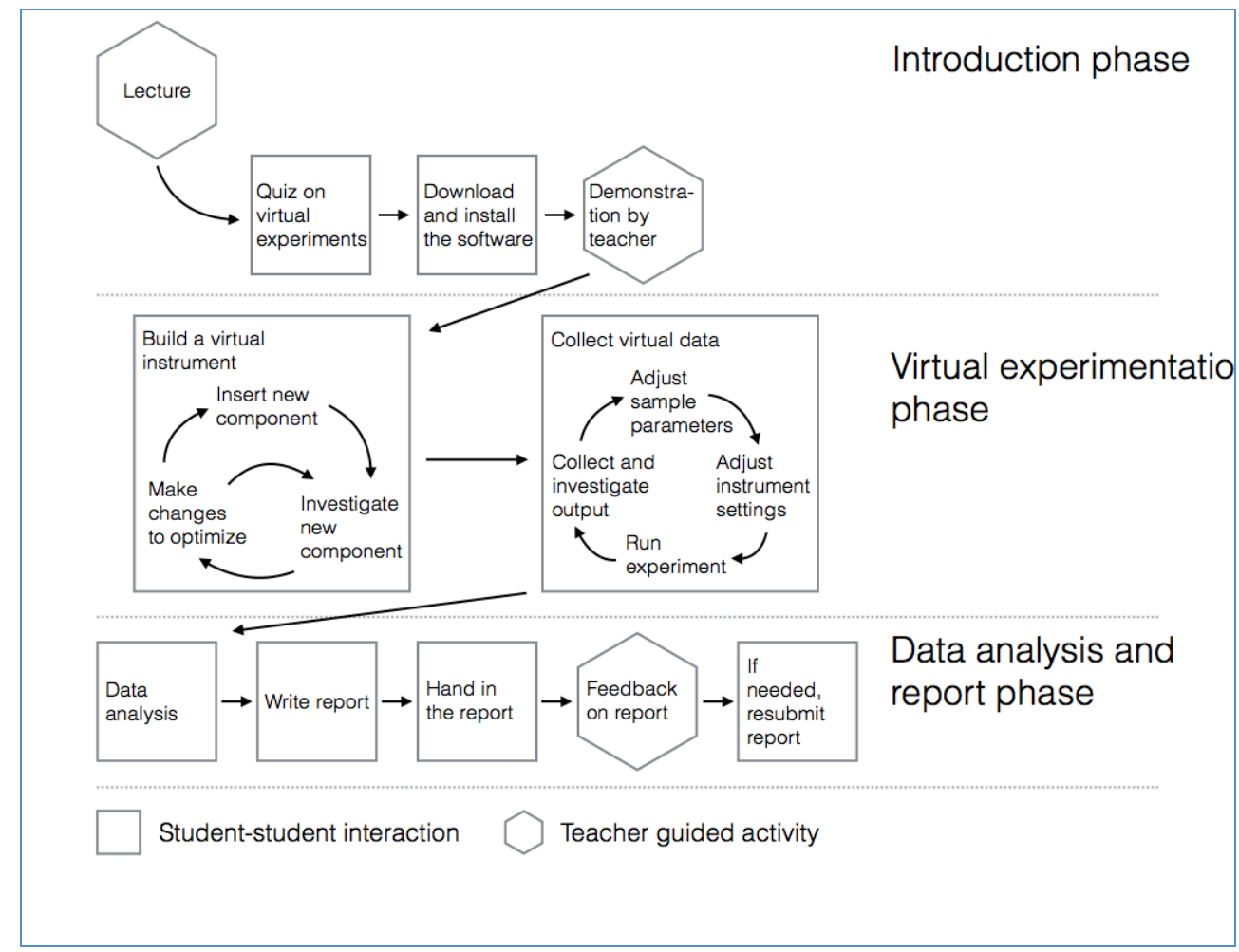

Figure 5. The structure of teaching with virtual experiments in the course.

The way virtual instruments are presented is shown in Figure 5. After having lectures on instrumentation (the hexagon in the upper left corner of Figure 5) the students are introduced to virtual experiments in a three-stage-manner. At first, they complete an online simulation quiz combined with an online 
predesigned instrument on the e-learning platform "e-neutrons.org" (the first square in the upper left corner). Here, the interface is an interactive visualisation of a generic computer interface to a neutron scattering instrument and the quiz questions are introductory. After this, students download and install McStas software on their own laptops and participate in a live-demonstration. In this demonstration, the teacher guides the class through building a simple instrument. This is the Introduction phase illustrated in the top row of Figure 5. After this, students work with three simulation projects (the Virtual experimentation phase). In these projects students build virtual reproductions of three real neutron scattering instruments located at the large-scale facility to be visited. They simulate the instruments from a set of requirements given by the teachers, implement a virtual sample into the simulation, and then run the virtual experiment. In the final phase, the Data analysis and report phase (bottom row), students analyse the data based on a set of explorative questions, and finally, write a report concluding on their results. During the three simulation projects the students stay in the same working groups. Throughout their work with simulations as just described, they need to interact with each other and with the teacher. The teacher strives to ask students open-ended questions that facilitate reflection and to encourage experimentation. Students also receive feedback. We believe that it is crucial to maintain a respectful, supportive, and safe environment for the students to make mistakes, but at the same time challenge students to think and act reflectively and learn from their mistakes.

\section{The trip to Switzerland}

In the hands-on week the students travel to the Paul Scherrer Institute (PSI) in Switzerland, which is a large-scale neutron scattering facility. Here, they help master- or PhD students conduct real experiments as part of on-going research projects. They do this at an instrument that corresponds to one they designed as virtual instruments. After the trip the students deliver a report, which often feeds directly into research and publications. During the hands-on week they act actively as neutron scattering scientists: They have to form and collaborate in scientific teams as well as exchange information and reports between teams in order to conduct the experiments. Usually one group of students, which is formed across the previous simulation groups (see above), participates in four days of beam time, after which the next group of students takes over the instrument and the experiment. Therefore, it is important for students to document and log everything they do; that they discuss, measure, conclude, and so on. This is where students get real experience with performing and reporting on experiments at large-scale facilities. After their stay at PSI, students hand in the final report where they describe the hands-on experiment they participated in and analyse relevant parts of the data that was obtained. 


\section{Realisation - Signs of learning}

The intended goals and the structure of the course are complex and manyfaceted. The goals involve competencies that can be expected on a master- and PhD-level, and part of these competencies is for students to identify with being a part of a community. Here, we use the theoretical framework we have used to inform the learning design to interpret student statements and answers to questions during interviews and in the questionnaire.

Many students seem to experience being on the brink of entering the community of neutron scattering, even if they choose not to do so later on:

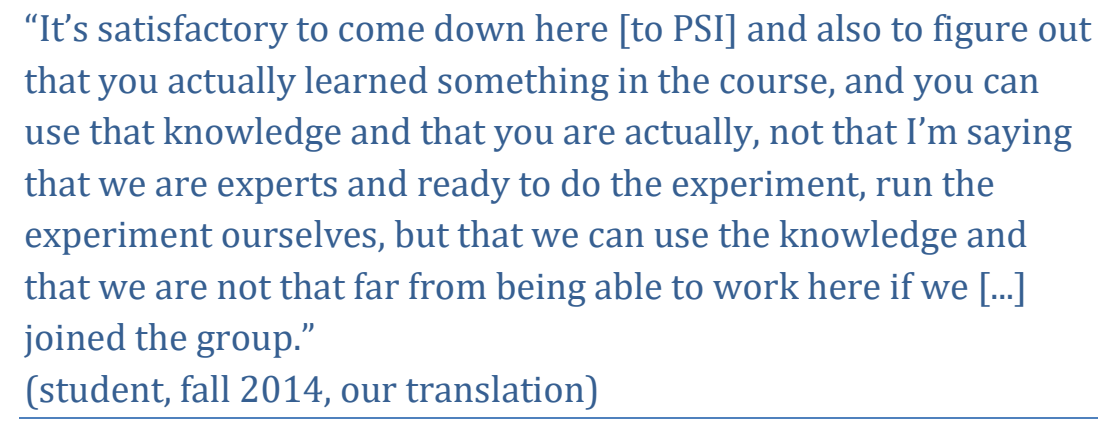

We see this as an example of how the course fosters legitimate peripheral participation. In terms of our view of competency, the student seems willing to participate in decision-making and can see herself as part of the scientific community. She experiences that the epistemic frame in which she has been trained is relevant to the epistemic frame she encounters at PSI. Also, the quote shows evidence of the student perceiving the situation as part of a new situation where the already developed tool-kit can be employed. But notice that it is more than a re-opening. The student seems to acknowledge that the next step is just within reach.

Students typically become more and more confident as the course progresses. At the end of the course they often utilize each other's competency in a collective way. From our framework's perspective, this means that they are training the epistemic frame, and we believe that this contributes to affective parts of their competency.

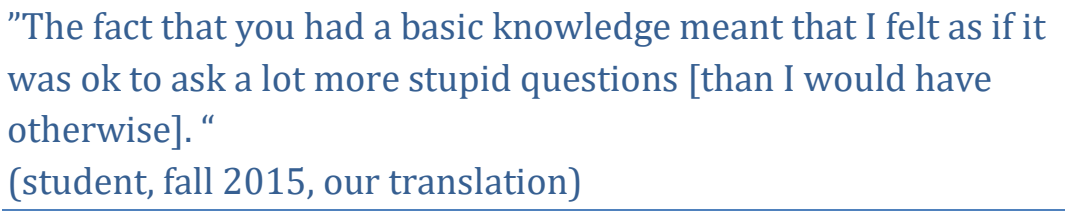

Having basic knowledge that appeared relevant to the situation made it ok to ask simple questions. While working with a simulation of experiment students may get an experience that the important thing is to understand the details of the instrument to make it work. This trains the epistemic frame in terms of knowledge, skills, and even values, and participating in this training is 
legitimate peripheral participation; their efforts give them an experience of becoming knowledgeable. And it is ok for knowledgeable people to ask simple questions.

At the university, students built virtual instruments and made virtual experiments. We believe that by doing this, students develop the intended competencies by increasing their programming skills and analytical skills. Because they use these skills to investigate exactly what they have programmed the software to do as a consequence of different input parameters, they are prepared to focus on the relation between the physics and the data of the experiment and how it relates to the rather than on just the instrumentation.

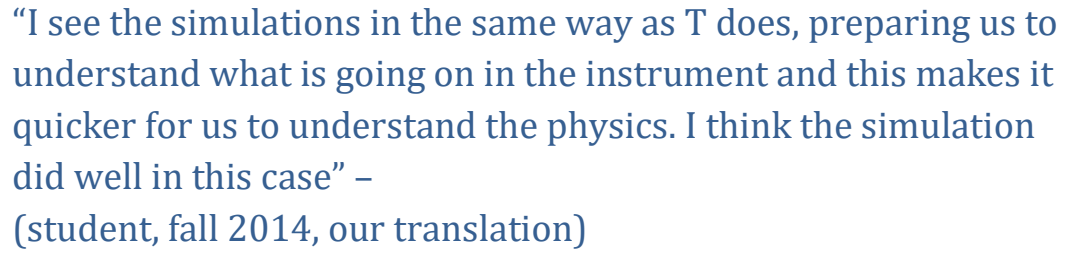

An analogy can be made to the cycles of expertise and Kolb's learning cycle. In terms of Gee's (2003) cycles of expertise, the skills that are taken for granted now is their ability to understand what goes on in the instrument, and students have to utilize this tool-box in order to proceed in the didactic game. The new elements of this game are the novel physics experiments and the new data. In terms of Kolb's learning cycle, their active experimentation with virtual experiments has enabled them to induce meaning to the new situation and create abstract conceptualisations.

It seems that working with the instrumentation virtually can actually transfer to working with instrumentation in real life. This has also been documented by Hougaard (2015), who found that student dialogues at PSI in contrast to in class back home shifted from being more about instrumentation to being more about physics.

\footnotetext{
"By having simulated RITA-II [a particular instrument], I got an understanding of how you even look at a triple-axisspectrometer in real life. You do not necessarily get an understanding of the physical entities (for example, distances between guide, sample and detector), but one can quickly create an overview of that. We have already processed how to understand the instrument. Without simulations it would have
} 
easily become difficult to comprehend, especially when shielding, wires and cables covered many of the important parts up. "

(student, fall 2015, our translation)

For this student there is a clear link between understanding the virtual instrument and understanding the real instrument. Being able to quickly visualise the physical entities is possible because students have already worked with visualising the instrument virtually. The visual aspects are hidden - covered by shielding, wires and cables - in the real instrument, so it is vital for the student to have a visual imagery surrounding the instrument. This is parallel to the finding of Barnett et al. (2000) for the Sun-Earth-Moon system. However, we also see evidence of limitations. First of all, what is transferred is closely related to what students have already done.

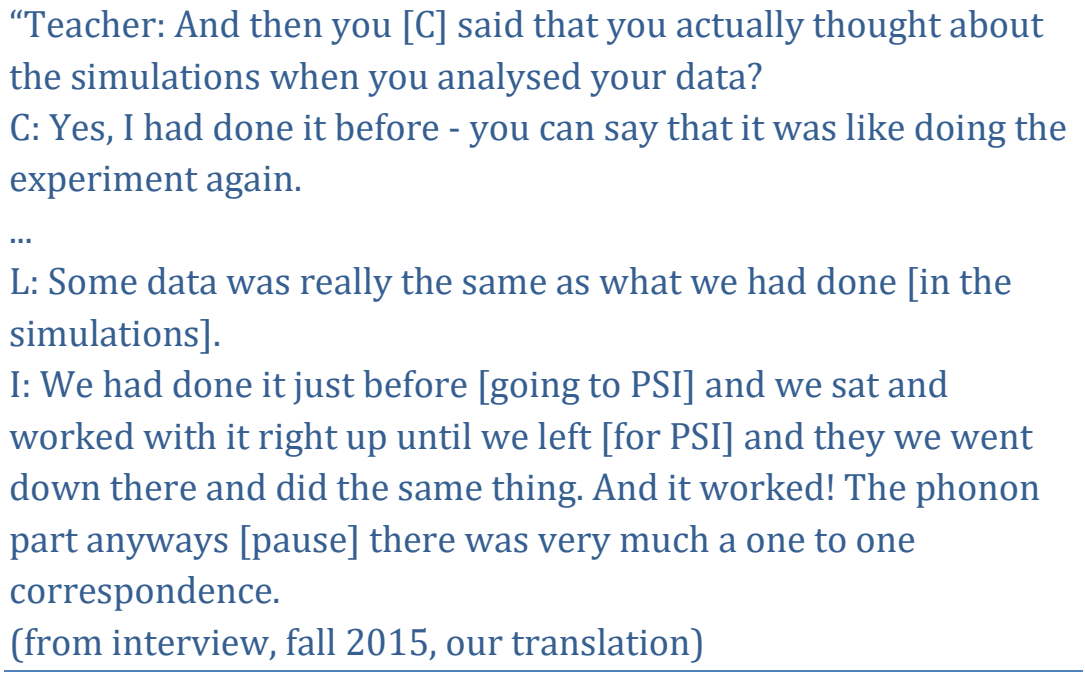

While students experience success and use what they have learned in the simulations, it almost seems like repetition to them. They are happy that it works, but it seems almost to be purely a consolidation of what they already knew. This means that what they learn is situated, and coming to PSI only partly removes the situatedness of what they learn:

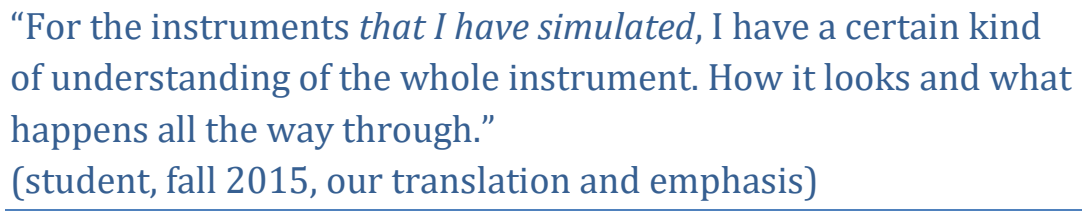

The student clearly acknowledges that he has learned a lot, but also specifies that it be for the instruments that he has simulated. Thus, despite some promising signs that students are training the epistemic frames of neutron scattering physicists, there are still numerous challenges to this learning design. As we have just shown, the transferred knowledge seems to be very closely related to what students have done back home. In terms of the learning cycle and cycles of expertise, it is difficult to know how much we can expect 
students to conceptualise the physics inherent to other instruments and experiments; whether other instruments and experiments would be on the growing edge of a student's competence. We (and they) cannot know how they will engage with other instruments and experiments.

Another challenge is that the instructions to the three simulation projects (done as part of the course back home) bear some resemblance to a cookbook exercise (Domin 1999). The components are introduced one by one, in a stepwise manner. After implementing each component the students are asked to examine the effect and feature of the component. This structure leaves very little for the students to discover and design themselves.

"I got a lot from putting in one component in at a time to see what
happens. But I also gain a lot from doing things. So in the
simulation, what does this thing do, why is this thing here, and so
on. In that way you get a good understanding of what the whole
instrument does and I think that it is essential that I don't just
close my eyes and push a button. That's what the exercise did -
that I knew what happened throughout the whole instrument."
(student, fall 2015, our translation and emphasis)

This exemplifies that students may like the very structured way of the exercises, but also have a need to think for themselves and do unplanned actions. It may also explain why one student above did not feel that he had necessarily learned much about the physical entities; if students focus on making the instrument work, it may not be relevant for them to consider the physics. This may put limits to the amount of reflection students can make even for the instruments they have actually worked with. The challenge then is to create tasks for the students in the didactical game, which 1) they can solve, 2) contributes to the toolkit, and 3) engages them in acting alone and with others within the epistemic frame of neutron scattering.

As we have hoped to show, the learning design we have employed have both benefits and limitations. In the next section we discuss some of the affordances of virtual experiments that we can derive from our observations.

\section{Affordances of virtual experiments}

We have divided our discussion into two parts. The first part focuses on the link between virtual and hands-on experiments; on how virtual experiments may affect hands-on learning. The second part relates affordances of virtual experiments to add nuance to rationales for doing practical work.

\section{The link between virtual and hands-on experiments}


Because the epistemology of physics is essentially experimental (Summers 1982), physicists gain knowledge through experiments, with a range from the Large Hadron Collider at CERN to deductive thought experiments. It is not surprising that physics education includes a range of experimental training. One of the roles of experiments or practicals is for students to experience physics phenomena (Kirschner 1992). This can be seen as part of Kolb's learning cycle, but must also include a link between cycles of expertise and the development of conceptual understanding and knowledge of abstract concepts and models.

We argue that virtual experiments, as a learning resource, can become an important actor in students' development of conceptual understanding in physics. One feature of a virtual experiment is the possibility to visualise and animate unobservable and/or invisible phenomena such as scattering phenomena of a neutron by different virtual instrument parts. This ability makes the interpretation of the physics involved in the experiment, virtual or hands-on, more perceptible and to some degree more tactile (De Jong, Linn, and Zacharia 2013). Most physics students can imagine neutrons as tiny balls that scatter from different instrument parts, following the laws of classical mechanics. But the neutrons also behave like waves due to the laws of quantum mechanics, and this may demand support to the students trying to form this picture. Virtual experiments afford different kinds of representations of unobservable phenomena. By experimenting virtually, students may gain an intuitive understanding and develop of their conceptual understanding of the physics involved. In the case of neutron scattering, students seem to get a sense of the "inner workings" of experiments, before seeing the real experimental setup.

Another important feature about virtual experiments is time efficiency. It will often take less time to setup a virtual experiment (on a predefined instrument) as compared to a complicated hands-on experiment. Furthermore, a virtual experiment can be cleverly tailored and optimised to be conducted on the timescale of seconds and minutes on modern personal computers, while a hands-on experiment may take hours or days and is limited by the actual materials at hand (in our case, for example, the flux of neutrons). This time effectiveness affords that the students can repeat the experiment several times, investigating more aspects of the physical phenomena operating in the system, being both instrumental and sample related. Thus, time and an "unlimited supply of materials" allow them to repeat cycles of learning and expertise as many times as they need in the training of the epistemic frame and thus their competencies. This can be utilised very fruitfully in teaching by allowing mistakes and having students work through these mistakes with just enough teacher guidance.

Moreover, virtual experiments can reduce the complexity of an experiment. The example of a student above being overwhelmed by the many wires and 
cables at PSI, is not unknown in upper secondary physics teaching where some teachers let students design circuits virtually before constructing them in real life (Bruun 2011). Common to the two situations is that students have some experience with the experimental setup and physics involved. In the case of neutron scattering, a combination of 3D animations of the virtual instrument and exercises on data analysis of the effect of the different instrument parts provide an overview of the actual instrument and of the scattering processes taking place in each instrument part.

The virtual setup has a major disadvantage, which is the fact that unanticipated events never happen in a virtual experiment. Students investigate what they programmed the software to do, as a consequence of different input parameters. In this sense, even if the outcome can only be predicted with a simulation, it is fixed. The danger here is that students may subsequently see a hands-on scientific result as a mistake, because it does not conform to what they have seen before. That is, if they believe the simulation model corresponds one-to-one with reality. Therefore, it is crucial for the learning designs that incorporate virtual experiments to make the transition to real experiments and to guide students through these.

\section{Relation to the rationale for practicals}

The literature sometimes expresses a frustration concerning the reasons and didactic design challenges regarding lab-exercises and hands-on exercises (Kirschner 1992). Especially the cookbook format has been subject to revision. Domin (1999) argues that in chemistry laboratory manuals a cookbook creates a shortcut in the cognitive skills needed to do the experiment, circumventing the utilization of higher-order cognitive skills; just as a catalyst in a chemical reaction. The course we have described makes use of a cookbook format, meaning that students need to follow the instructions. On the other hand, if they are left to openly explore the program, they are likely to not learn the features necessary for them to create and conduct specific virtual experiments. As noted by Tamir (1989), there is a balance between open and closed instruction to be considered. The challenge is that the simulations require programming skills and knowledge about instrumentation of neutron scattering instruments.

This relates to the common rationales for practicals (Jacobsen 2008). We suggest that virtual experiments could be used to carry out Jacobsen's (2008) idea that practicals can be used as a way of solving physics problems, rather than for examples illustrating theories or developing experimental skills. For example, the problem could be related to the microscopic nature of friction (Bodin 2012). Software exists that will allow students to create virtual microscopic models of friction and run them to test hypotheses. Just as with neutron scattering, students run models of things they would not be able to see otherwise. The models are based on our understanding of how things 
behave at the microscopic level, and they take the form of experiments in the virtual world.

The challenge remaining is to construct problems that appear as a natural part of the didactic game; problems, which on one hand allow students to cyclically train the epistemic frame by learning for example relevant skills, values and concepts while on the other hand continuously being on the edge of students' competencies.

\section{Concluding remarks}

We have presented a learning design for teaching students to engage meaningfully and fruitfully with experimental setups at large-scale neutron scattering facilities. The motivation for creating this learning design was that these kinds of experiments are expensive and beam time is a sparse resource. In our design we have used an experiential learning method, which included considerations of students becoming legitimate peripheral participants and transferring knowledge from one learning situation to another. We have presented student reflections that show how at least some students do feel like legitimate peripheral participants, that many students felt that they got an intimate understanding of particular instruments, and that they could use that understanding to focus their attention on the relevant physics principles and data. Using these signs of what students have learned as a starting point, we have further discussed the affordances of virtual experiments: that they can allow students to see things that are otherwise not seen, they allow for making many mistakes and thus more for students to go through learning cycles multiple times. They also reduce complexity, which can help students when they face hands-on experiments. However, challenges remain when using virtual experiments, and we have pointed to cookbook exercises and the fact that a virtual experiment will never produce truly unexpected results as two such challenges.

In the next implementation(s) of the course we plan to implement further exercises, which are based on online (predefined) virtual experiments as well as transform the existing cookbook exercises to a format, which to a larger extent allows the students to design and discover for themselves. In a future research project, we intend to compare the transfer and skills achieved by these transformed exercises to those achieved by the traditional ones. 


\section{References}

Barnett, M., Keating, T., Barab, S. A., and Hay, K. E. (2000). Conceptual change through building three-dimensional virtual models. In Fourth International Conference of the Learning Sciences. Edited by: Fishman, B. and O'Connor-Divelbiss, $S$ (pp. 134-141).

Bodin, M. (2012). Mapping university students' epistemic framing of computational physics using network analysis. Physical Review Special Topics-Physics Education Research, 8(1), 010115.

Bruun, J. (2011). ATD and CoP in a framework for investigating social networks in physics classrooms. Peer reviewed papers from a PhD course at the University of Copenhagen, 2010, 31.

Bruun, J. (2012). Networks in Physics Education Research (Doctoral dissertation, Ph. D. thesis, University of Copenhagen).

Danish Ministry of Education (2016). Introduktion til den danske kvalifikationsramme for livslang læring. Retrieved August 26. 2016 from:

https://www.uvm.dk/Service/Publikationer/Publikationer/Uddannels e-og-undervisning-for-voksne/2010/kvalifikationsramme-stor/Hvader-den-danske-kvalifikationsramme

De Jong, T., M. C. Linn and Z. C. Zacharia (2013). Physical and virtual laboratories in science and engineering education. Science 340(6130): 305-308.

Dolin, J. (2002). Fysikfaget i forandring. (Danish only) PhD thesis. Roskilde University, Denmark.

Domin, D. S. (1999). A content analysis of general chemistry laboratory manuals for evidence of higher-order cognitive tasks. Journal of Chemical Education 76(1): 109.

Gee, J. P. (2003). What video games have to teach us about learning and literacy. Computers in Entertainment (CIE), 1(1), 20-20.

Hougaard, J. (2015). Using virtual experiments as a preparation for largescale facility experiments, Master's thesis, Department of Science Education, University of Copenhagen (2015).

Jacobsen, L. B. (2008). Formål med eksperimentelt arbejde i fysikundervisningen. MONA, 4, 22-41.

Kirschner, P. A. (1992). Epistemology, practical work and academic skills in science education. Science \& Education 1(3): 273-299.

Kolb, A. Y. and Kolb, D. A. (2012). Experiential learning theory. In Encyclopedia of the Sciences of Learning (pp. 1215-1219). Springer US.

Kolb, D. A. (2014). Experiential learning: Experience as the source of learning and development. FT press. 
Kvale, S. (2007). Doing interviews. London: SAGE Publications.

Lave, J. and Wenger, E. (1991). Situated learning: Legitimate peripheral participation. Cambridge university press.

Lefmann, K., P. K. Willendrup, L. Udby, B. Lebech, K. Mortensen, J. O. Birk, K. Klenø, E. Knudsen, P. Christiansen and J. Saroun (2008). Virtual experiments: the ultimate aim of neutron ray-tracing simulations. Journal of Neutron Research 16(3-4): 97-111.

Lefmann, K. and Nielsen, K. (1999). "McStas, a General Software Package for Neutron Ray-tracing Simulations", Neutron News 10, 20.

Lowe, R. (2001). Understanding information presented by complex animated diagrams. Multimedia learning-Cognitive and instructional issues, 65-74.

May, M. and Achiam, M.F. (2013), Virtual Laboratories in Chemistry, Biochemistry \& Molecular Biology. Unpublished report, Department of Science Education, University of Copenhagen, pp. 1-74.

Mason, A., Yerushalmi, E., Cohen, E., and Singh, C. (2016). Learning from mistakes: The effect of students' written self-diagnoses on subsequent problem solving. The Physics Teacher, 54(2), 87-90.

Rebello, N. S., Zollman, D. A., Allbaugh, A. R., Engelhardt, P. V., Gray, K. E., Hrepic, Z., and Itza-Ortiz, S. F. (2004). Dynamic transfer: A perspective from physics education research. Transfer of Learning: Research and Perspectives. Greenwich: Information Age Publishing.

Rolfe, J. M., and Staples, K. J. (1988). Flight simulation (No. 1). Cambridge University Press.

Shaffer, D. W., Hatfield, D., Svarovsky, G. N., Nash, P., Nulty, A., Bagley, E., Frank, K, Rupp, A. A. and Mislevy, R. (2009). Epistemic network analysis: A prototype for 21st-century assessment of learning. International Journal of Learning and Media 1(2), 1-22.

Summers, M. (1982). Science Education and Meaningful Learning. School Science Review 64(227): 361-366.

Tamir, P. (1989). Training teachers to teach effectively in the laboratory. Science education 73(1): 59-69.

University of Copenhagen (2016): NFYK13021U Neutron Scattering. Retrieved August 26th, 2016 from https://kurser.ku.dk/course/nfyk13021u/2015-2016

Udby, L., P.K. Willendrup, E. Knudsen, Ch. Niedermayer, U. Filges, N.B. Christensen, E. Farhi, B.O. Wells, K. Lefmann (2011). Analysing neutron scattering data using McStas virtual experiments. Nuclear Instruments and Methods in Physics Research A 634: S138-S143 
Udby, L., P. Jensen, J. Bruun, P. Willendrup, H. Schober, J. Neuhaus, J. S. B. Nielsen, J. Pulz and K. Lefmann (2013). E-learning neutron scattering. Neutron News 24(1): 18-23.

Willendrup, P., Farhi, E., Knudsen, E., Filges, U., and Lefmann, K. (2014). McStas: Past, present and future. Journal of Neutron Research, 17(1), 3543.

Winsløw, C. (2006). Didaktiske elementer-En indføring i matematikkens og naturfagenes didaktik. Biofolia. 